\title{
A predictive model for extubation readiness in extremely preterm infants
}

\author{
Dhruv Gupta $\mathbb{1}^{1} \cdot$ Rachel G. Greenberg $\mathbb{( D}^{2} \cdot$ Amit Sharma ${ }^{1} \cdot$ Girija Natarajan ${ }^{1} \cdot$ Michael Cotten $^{2} \cdot$ Ronald Thomas $^{1}$. \\ Sanjay Chawla ${ }^{1}$
}

Received: 7 May 2019 / Revised: 1 July 2019 / Accepted: 11 July 2019 / Published online: 27 August 2019

(c) The Author(s), under exclusive licence to Springer Nature America, Inc. 2019

\begin{abstract}
Objective To develop an estimator for predicting successful extubation for an individual preterm infant.

Study design This was a retrospective study that included infants with birth weights $\leq 1250 \mathrm{~g}$, who were admitted to a tertiary NICU over a 7-year period, received mechanical ventilation and had an elective extubation attempt within 60 days of age. Perinatal and periextubation characteristics were compared in the successful and failed extubation groups.

Results Of 621 screened infants, 312 were included. Extubation succeeded in $73 \%$ and failed in $27 \%$. Adjusted factors associated with successful extubation included greater gestational age, chronologic age, pre-extubation $\mathrm{pH}$ and lower preextubation $\mathrm{FiO}_{2}$, along with lower "peak" respiratory severity score in the first $6 \mathrm{~h}$ of age.

Conclusions We used readily available demographic and clinical data to create an extubation readiness estimator that provides the probability of extubation success for an individual preterm infant (http://elasticbeanstalk-us-east-2676799334712.s3-website.us-east-2.amazonaws.com/).
\end{abstract}

\section{Introduction}

Most extremely preterm (gestational age $<28$ weeks) infants receive mechanical ventilation (MV) to maintain oxygenation and ventilation [1]. Although MV is life-sustaining, prolonged MV has been associated with higher rates of mortality and neonatal morbidities, including upper airway injury and nosocomial infections [1-4]. A long cumulative duration of MV in extremely low-birth-weight infants $(<1000 \mathrm{~g})$ is associated with an increased risk of bronchopulmonary dysplasia (BPD) [5]. Each additional week of MV has been associated with an increased risk of neurodevelopmental impairment [2]. It has been suggested that early extubation from MV may reduce the risk of some of these complications

Supplementary information The online version of this article (https:// doi.org/10.1038/s41372-019-0475-x) contains supplementary material, which is available to authorized users.

Sanjay Chawla

schawla@dmc.org

1 Department of Pediatrics, Wayne State University, Detroit, MI, USA

2 Department of Pediatrics, Duke University, Durham, NC, USA
$[3,4,6]$. However, up to $50 \%$ of extremely preterm infants fail extubation, even when extubation criteria, such as level of ventilator support and respiratory function parameters, are met [7-9]. A significant proportion (15-20\%) of extremely low-birth-weight infants may be exposed to three or more courses of MV before discharge from neonatal intensive care units [10]. Failed extubation has been noted to be independently associated with increased rates of severe intracranial hemorrhage, mortality, BPD, death or BPD, longer hospitalization, and longer duration of supplemental oxygen and ventilator support [7, 11-13]. Therefore, the goal for extremely preterm infants receiving MV support is early and successful extubation.

Currently, the decision to extubate a preterm infant relies primarily on clinical judgment. Because of a lack of standardized guidelines, NICUs vary significantly in their periextubation practices, including timing of extubation, postextubation respiratory support, and criteria for reintubation $[14,15]$. Previous studies have evaluated the risk factors associated with extubation failure [7, 9, 13, 16, 17]. However, currently there is no objective estimator that can calculate the probability of successful extubation for any individual patient.

The aim of this study was to identify perinatal and periextubation clinical characteristics associated with 
successful elective extubation and to develop an estimator for predicting successful extubation for an individual preterm infant.

\section{Methods}

\section{Study design}

This was a retrospective, cohort study that included preterm infants born at Hutzel Women's Hospital, Detroit, MI, from January 2009 to December 2015. The study was approved by the institutional review board at Wayne State University.

\section{Study population}

All preterm infants with birth weight $<1250 \mathrm{~g}$ who were admitted to the tertiary level NICU at Hutzel Women's Hospital were screened. Infants were eligible for the study if they (1) received MV via an endotracheal tube, and (2) had a first elective extubation attempt within 60 days of birth. Infants who died before an extubation attempt was made were not eligible for the study and those who had missing data regarding success of the extubation, or those who were part of an ongoing multicenter study evaluating extubation readiness, were excluded from the analysis. The decisions for initial endotracheal intubation, timing of extubation, postextubation support, and need for reintubation were at the discretion of the clinical team.

\section{Definitions}

The primary outcome was successful extubation, defined as survival for 5 or more days without the need for respiratory support from an endotracheal tube.

Ventilation index was used as an objective measure of ventilation in response to the respiratory support provided. Ventilation index was calculated as the product of the set rate, partial pressure of carbon dioxide in arterial or capillary blood $\left(\mathrm{PCO}_{2}\right)$, and the difference between peak inspiratory and positive end-expiratory pressure divided by 1000 [18]. Respiratory severity score (RSS) was used as an objective marker of oxygenation in response to respiratory support provided, and was calculated as the product of the mean airway pressure and fraction of inspired oxygen $\left(\mathrm{FiO}_{2}\right)[19]$.

Gestational age was estimated based on best obstetric approximation using early ultrasonography findings, date of last menstrual period, or modified Ballard score, in that order [20]. Presence of acute chorioamnionitis was determined based on histologic findings of acute chorioamnionitis or funisitis on placental pathology. Postextubation respiratory support was categorized as NCPAP/NIPPV or nasal cannula.
The practice at Hutzel Women's Hospital through the study period was to use noninvasive ventilation when possible, and to limit endotracheal intubation and MV to infants who were apneic or failed a noninvasive ventilation attempt. High-frequency oscillatory ventilation was used as a rescue modality for MV. Clinicians usually would attempt extubation of extremely preterm infants at ventilator rates of 16-20 breaths per minute, mean airway pressure of $<8 \mathrm{~cm}$ $\mathrm{H}_{2} \mathrm{O}$, and $\mathrm{FiO}_{2}$ below 0.4 , with blood gas $\mathrm{pH}>7.25$ and $\mathrm{PCO}_{2}<60 \mathrm{mmHg}$. Usual practice in our center was to consider reintubation if patients had significant and recurrent apnea (more than 3 per hour or requiring bag and mask ventilation), increased work of breathing with respiratory acidosis (blood gas $\mathrm{pH}<7.20$ and $\mathrm{PCO}_{2}>65 \mathrm{mmHg}$ ).

\section{Statistical analysis}

Perinatal and periextubation characteristics of those who failed the first extubation attempt and those who were successful were compared. Categorical variables in the two groups were compared using the $\chi^{2}$ test or Fisher exact test where appropriate, and continuous variables were analyzed using the Wilcoxon rank-sum test. A logistic regression model was created to determine variables associated with successful extubation. Variables in the logistic regression analysis were selected based on a backward selection method (all covariates were initially included, and then nonsignificant covariates were removed if the $P$ value was $>0.2$. We validated our model, using a bootstrapping validation technique with 200 replications in order to estimate distribution-free standard errors and confidence intervals. We applied the results of our model to our cohort to estimate the probability of extubation success and calculated the sensitivity and specificity of cutoffs of 60,70 , and $80 \%$ probability of success. As a sensitivity analysis, we repeated the model using an alternate definition of successful extubation (survival for $\geq 72 \mathrm{~h}$ without reintubation). Statistical analysis was conducted using Stata version 15.1 (StataCorp, College Station, TX).

\section{Results}

During the study period, there were 621 infants delivered with birth weight $\leq 1250 \mathrm{~g}$. Of these 621 infants, 20 infants received comfort care only, 117 remained on noninvasive respiratory support, 87 died prior to extubation, 9 infants were never extubated and were discharged home on ventilator, 1 patient had missing data, and 387 infants were extubated. Among the 387 patients that were identified to have extubations, 348 had an elective extubation and 33 were unplanned (data were missing on elective vs. planned extubation for 6 patients). The median GA of infants who 


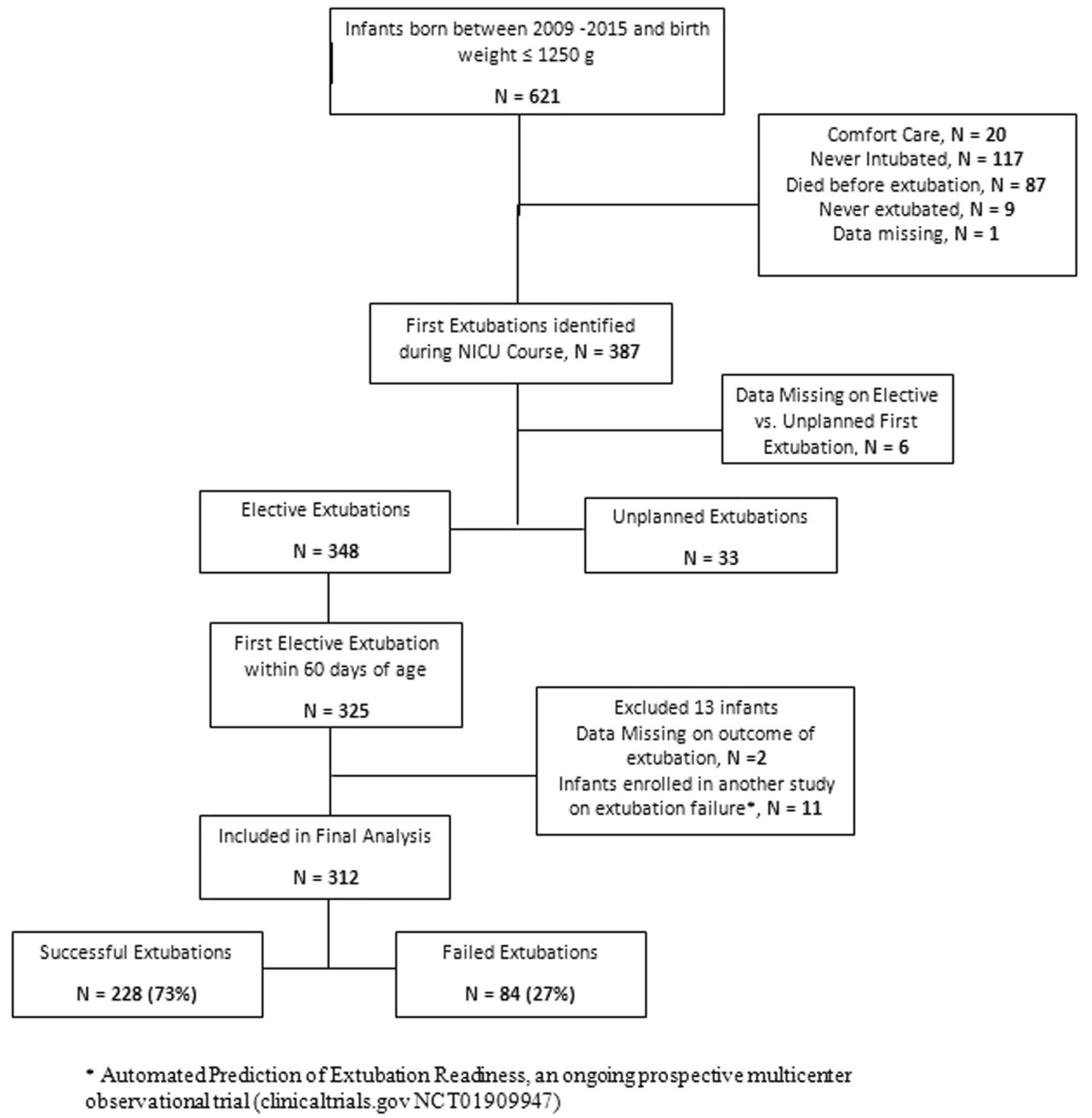

Fig. 1 Flow diagram of infant population

remained on noninvasive respiratory support was 29 weeks with interquartile range (IQR) of 28-30 weeks and 49/117 $(42 \%)$ were male. Infants who had unplanned extubation had median GA of 26 weeks with IQR of 24-28 weeks and 16/33 (49\%) were male. 325 infants were electively extubated within first 60 days of age. Of 325 infants, 13 were excluded [ 2 had missing data and 11 were part of another study on extubation readiness-Automated Prediction of Extubation Readiness (clinicaltrials.gov NCT01909947)]. Three hundred and twelve infants were included in the final analysis; extubation succeeded in $228(73 \%)$ and failed in 84 (27\%) (Fig. 1).

Among those who failed extubation within 5 days, most $(75 / 84,89 \%)$ underwent reintubation within 72 h. (Fig. 2).

\section{Factors associated with successful extubation}

On unadjusted analysis, successfully extubated infants had a higher gestational age, higher birth weight, lower incidence of histologic chorioamnionitis, and lower peak RSS in the first $6 \mathrm{~h}$ of age (Table 1). In our institution at the time of data collection, we did not practice intubation-surfactantextubation (INSURE) or less invasive surfactant instillation. Among 228 infants with successful extubation, 167/227 (74\%) were intubated in the delivery room (DR) and 215 (94\%) were intubated within first 7 days of age; one patient had missing data on DR intubation. Among 84 infants who failed extubation, $71 / 82(87 \%)$ were intubated in the DR and $82(98 \%)$ were intubated within first 7 days of age. Two 


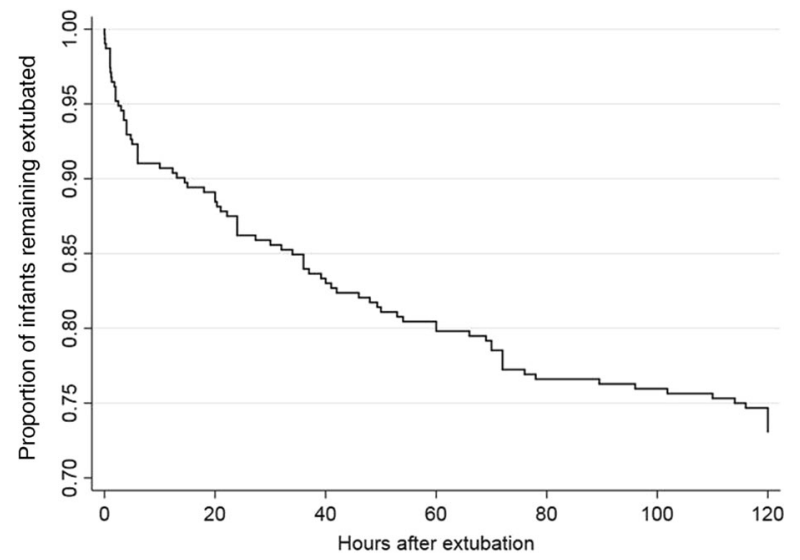

Fig. 2 Kaplan-Meier curve showing proportion of infants remaining extubated: Among those who failed extubation within 5 days, $89 \%$ underwent reintubation within $72 \mathrm{~h}$

infants did not have data on DR intubation as they were born at home.

At the time of extubation, infants in the successful extubation group had a higher postmenstrual age, weight at extubation, and pre-extubation blood gas $\mathrm{pH}$, along with lower pre-extubation $\mathrm{FiO}_{2}$ and pre-extubation RSS. A lower proportion of infants who had successful extubation received NCPAP or NIPPV compared with infants who failed extubation (Table 1).

\section{Adjusted analysis}

In multiple logistic regression analysis, successful extubation was associated with higher gestational age, higher chronologic age at extubation, higher blood gas $\mathrm{pH}$, and lower pre-extubation $\mathrm{FiO}_{2}$ and $\mathrm{RSS}$ in the first $6 \mathrm{~h}$ of age. The area under the curve for the prediction model was 0.77 (Table 2). Our sensitivity analysis using a definition of successful extubation of $\geq 72 \mathrm{~h}$ without reintubation identified the same significant covariates (Supplementary Table 1). We found that the model had sensitivity/ specificity of $87 \% / 53 \%, 76 \% / 66 \%$, and $54 \% / 81 \%$ for cutoffs of $60 \%, 70 \%$, and $80 \%$ probability of extubation success, respectively.

Using this logistic regression model, we created an estimator to predict extubation success, in which clinicians can enter clinical variables to determine the chances of successful extubation (http://elasticbeanstalk-us-east-2-676799334712. s3-website.us-east-2.amazonaws.com/). A snapshot of the extubation readiness estimator is shown in Fig. 3.

\section{Discussion}

We noted a $27 \%$ rate of failed elective extubation among extremely preterm infants within the first 60 days of age. The
Table 1 Characteristics of infants who had a successful or failed extubation

\begin{tabular}{|c|c|c|c|}
\hline \multirow[t]{2}{*}{ Variable $^{\mathrm{a}}$} & \multicolumn{2}{|l|}{ Extubation } & \multirow[t]{2}{*}{$P$ value } \\
\hline & $\begin{array}{l}\text { Success } \\
(n=228)\end{array}$ & Failure $(n=84)$ & \\
\hline GA (weeks) & $27(26-28)$ & $26(25-27)$ & $<0.001$ \\
\hline Birth weight $(\mathrm{g})$ & $931(790-1090)$ & 815 (690-914) & $<0.001$ \\
\hline Complete ANS course & $142 / 226(63 \%)$ & $54 / 83(65 \%)$ & 0.72 \\
\hline Histologic chorioamnionitis & $100 / 213(47 \%)$ & $46 / 76(61 \%)$ & 0.04 \\
\hline Vaginal delivery & $68(30 \%)$ & $23(27 \%)$ & 0.67 \\
\hline Male sex & $115(50 \%)$ & $43(51 \%)$ & 0.90 \\
\hline Peak RSS in first $6 \mathrm{~h}$ & $3.6(2.5-4.6)$ & $3.8(2.7-6.3)$ & 0.03 \\
\hline Apgar $\leq 6$ at $5 \mathrm{~min}$ & $82(37 \%)$ & $39(48 \%)$ & 0.08 \\
\hline African-American race & $186(83 \%)$ & $65(78 \%)$ & 0.39 \\
\hline $\begin{array}{l}\text { Surfactant administration } \\
\text { after birth }\end{array}$ & $142(62 \%)$ & $52(62 \%)$ & 0.21 \\
\hline Maternal PIH & $61(27 \%)$ & $20(24 \%)$ & 0.60 \\
\hline Age at extubation (days) & $3(2-9)$ & $4(2-9)$ & 0.25 \\
\hline PMA at extubation (weeks) & $28(27-29)$ & $27(26-28)$ & $<0.001$ \\
\hline Weight at extubation (g) & $970(810-1100)$ & $810(700-980)$ & $<0.001$ \\
\hline Pre-extubation VI & $5.8(4.2-7.3)$ & $5.4(4.3-7.8)$ & 0.63 \\
\hline Pre-extubation $\mathrm{pH}$ & $\begin{array}{l}7.36 \\
(7.31-7.41)\end{array}$ & $\begin{array}{l}7.33 \\
(7.29-7.38)\end{array}$ & 0.002 \\
\hline Pre-extubation $\mathrm{PCO}_{2}$ & $36(30-42)$ & $38(31-43)$ & 0.12 \\
\hline Pre-extubation $\mathrm{FiO}_{2}(\%)$ & $23(21-28)$ & $25(21-30)$ & $<0.001$ \\
\hline Pre-extubation RSS & $1.4(1.2-1.8)$ & $1.6(1.4-1.8)$ & 0.005 \\
\hline Pre-extubation ventilation rate & $15(14-16)$ & $14(14-16)$ & 0.87 \\
\hline Pre-extubation MAP & $6.0(5.6-6.7)$ & $6.1(5.5-6.6)$ & 0.91 \\
\hline Pre-extubation PIP & $15(14-16)$ & $14(14-16)$ & 0.16 \\
\hline $\begin{array}{l}\text { Postextubation respiratory } \\
\text { support (NIPPV/NCPAP vs. } \\
\text { others }^{b} \text { ) }\end{array}$ & $148(65 \%)$ & $65(78 \%)$ & 0.02 \\
\hline $\begin{array}{l}\text { Use of caffeine before } \\
\text { extubation }\end{array}$ & $187(82 \%)$ & $75(89 \%)$ & 0.12 \\
\hline
\end{tabular}

$A N S$ antenatal steroids, $G A$ gestational age, $P I H$ pregnancy-induced hypertension, $P M A$ post menstrual age, $R S S$ respiratory severity score, $\mathrm{FiO}_{2}$ fraction of inspired oxygen, MAP mean airway pressure, NCPAP nasal continuous positive airway pressure, NIPPV nasal intermittent positive pressure ventilation, $P I P$ peak inspiratory pressure, RSS respiratory severity score, $V I$ ventilation index

${ }^{\mathrm{a}}$ Data are given as median (interquartile range) or $\mathrm{n} / \mathrm{N}(\%)$

bothers include high-flow nasal cannula, nasal cannula, and room air

results are consistent with previously published extubation failure rates among extremely preterm infants [7, 9, 13].

Only infants who underwent elective extubation within the first 60 days of age were included, because the factors affecting success and failure of extubation may be different in older patients with established BPD and higher risk of airway complications compared with younger infants.

In the current study, older gestational age, older age at extubation, higher blood gas $\mathrm{pH}$ before extubation, and lower pre-extubation $\mathrm{FiO}_{2}$, along with lower values for the highest RSS in the first $6 \mathrm{~h}$ of age were associated with successful extubation on adjusted analysis. RSS in the initial hours after birth was used as a surrogate for severity of respiratory illness at birth. Many of these findings have intuitive merit. 
Previous studies have noted higher postmenstrual age, lower $\mathrm{FiO}_{2}$, lower $\mathrm{PCO}_{2}$, lower oxygenation index, and higher gestational age to be associated with extubation success $[7,9,13,16,17]$. Two of these studies $[7,13]$ were secondary analyses of randomized controlled trials, where a significant proportion (nearly $60 \%$ in one trial [21] and $36 \%$ in the other trial [22]) of eligible infants could not be included in the extubation readiness analysis for various reasons, including unavailability of research staff and parental refusal. Exclusion of large proportion of eligible infants may limit the generalizability of findings. The current study included most eligible patients during the study period born recently in a single center. Three other previous studies on extubation failure, had limited number of patients; one of them had a total of 52 patients [9], other had a total of 41 patients [16], and the third

Table 2 Adjusted markers of successful extubation (defined as $\geq 5$ days without reintubation)

\begin{tabular}{|c|c|c|c|}
\hline$\overline{\text { Effect }}$ & Odds Ratio & $95 \% \mathrm{CI}$ & $P$ value \\
\hline Gestational age (weeks) & 1.50 & $1.16-1.94$ & 0.002 \\
\hline Age at extubation (days) & 1.04 & $1.01-1.08$ & 0.02 \\
\hline $\mathrm{pH}$ at extubation ${ }^{\mathrm{a}}$ & 1.68 & $1.03-2.76$ & 0.04 \\
\hline Weight at extubation (g) & 1.002 & 0.999-1.004 & 0.19 \\
\hline $\mathrm{FiO}_{2}$ at extubation ${ }^{\mathrm{b}}$ & 0.93 & $0.88-0.98$ & 0.01 \\
\hline Peak RSS in first $6 \mathrm{~h}^{\mathrm{c}}$ & 0.88 & $0.78-0.98$ & 0.048 \\
\hline
\end{tabular}

CI confidence interval, $\mathrm{Fio}_{2}$ fraction of inspired oxygen, $\mathrm{RSS}$ respiratory severity score

${ }^{\mathrm{a} O d d s}$ ratio represents increased odds per increase in $\mathrm{pH}$ of 0.1

${ }^{b}$ Odds ratio represents decreased odds per increase in $\mathrm{FiO}_{2}$ by $1 \%$

${ }^{c}$ Odds ratio represents decreased odds per increase in peak RSS by 1 had a total of 82 patients [17]. The current study provides detailed description of clinical characteristics, respiratory support and blood gas parameters both at birth and periextubation period in a large cohort of preterm infants.

A few studies have assessed extubation readiness by considering pre-extubation lung compliance, functional residual capacity, heart rate variability, and use of spontaneous breathing trial [23-30]. However, the use of these pulmonary function measures alone or in combination has been noted to have low predictive value and limited benefit clinically for assessment of extubation readiness in preterm infants [14].

The extubation readiness estimator developed in the current study may be applied to individual infants using simple, bedside clinical variables. Estimators of morbidities such as BPD and early-onset sepsis in neonates have been previously developed and have good clinical utility [31, 32]. Use of our extubation readiness estimator may help achieve extubation earlier in some infants with a high chance of success when clinicians might have opted to delay extubation. Also, patients with a high probability of failure based on this extubation readiness estimator may benefit from preextubation assessment and treatment for coexisting conditions such as lung atelectasis, congestion, and apnea. A higher level of noninvasive support, optimal dose of caffeine, close observation for respiratory distress, and escalation of noninvasive support may also improve chances for successful transition to noninvasive respiratory support.

A recent systematic review noted that prophylactic methylxanthines reduce the rate of extubation failure in premature infants [33]. We included caffeine use before extubation in the analysis but did not find a significant
Fig. 3 A snapshot of the online extubation readiness estimator: The information provided on this website is for illustration purposes only and not meant as a substitute for professional medical care

\section{Extubation Success Calculator}

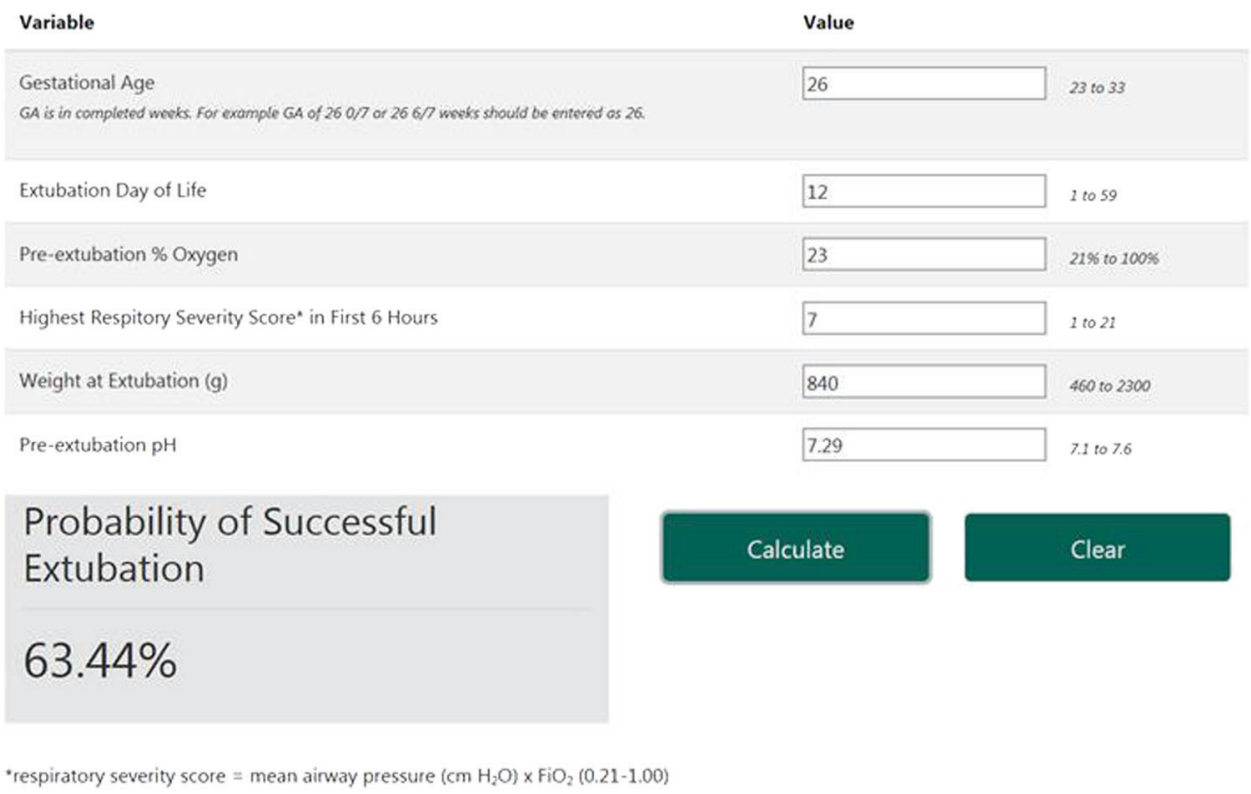


difference between the two groups, likely because of very high rates of caffeine administration in our NICU before extubation was attempted (prevalence of caffeine in extubation success vs failure: 82 vs $89 \% ; P=0.12$ ).

During the study period, the interface to provide CPAP and NIPPV was nasal prongs. Use of NIPPV or CPAP was combined in one group and was compared with other modes of respiratory support that included nasal cannula or high-flow nasal cannula. We noted that a higher proportion of infants underwent extubation to NIPPV/NCPAP in the group that failed extubation (78\%) compared with the successful extubation group (65\%). Use of NIPPV has been associated with higher rates of successful extubation in randomized controlled trials [33]. Because this was an observational study, we speculate that the higher use of NIPPV/NCPAP among the failed extubation group was associated with increased clinician preference for use in infants with immaturity and severity of lung disease of the patients in the failed extubation group.

There is no consensus on the definition of extubation success for premature infants. We defined extubation failure as the need for reintubation within 5 days instead of shorter (2-3 days) of extubation, because a significant proportion (25\%) of infants might fail extubation 48-72 h later [7]. Studies have used empiric criteria to define extubation failure, such as the need for reintubation within intervals ranging from $72 \mathrm{~h}$ to 7 days [8]. Extending the definition of extubation failure to a duration beyond 5 days carries the risk of including infants who fail extubation due to new and unforeseen morbidities, such as pneumonia, sepsis, or necrotizing enterocolitis rather than the underlying respiratory disease.

Given the lack of consensus on the definition of extubation failure in neonates, we reran the model using a definition of successful extubation as need for reintubation within $72 \mathrm{~h}$ of extubation. On analysis with this different definition of extubation success, we noted that the same predictive factors were identified with similar estimates as with our original analysis.

Use of the extubation readiness estimator may help health care providers achieve early successful extubation in preterm infants, and may reduce duration of MV and associated complications, including BPD and airway injuries.

Currently, the optimal probability of the success at which health care providers should attempt extubation is not known. Further studies using this estimator to determine the optimal threshold probability of extubation success as well as the risk of short-term morbidities, including BPD, would be useful.

This study had limitations. This was a single center cohort study and different sites may have different extubation and reintubation practices that limit the generalizability of the model. Although general guidelines were followed by clinicians at Hutzel Women's Hospital, endotracheal intubation, extubation, and reintubation were at the discretion of the primary clinical team. We did not explore the reasons for extubation failure that could also contribute toward the timing and probability of extubation failure. We did not perform a separate analysis based on the timing of reintubation other than the predefined criteria of 5 days. We included elective extubations within an arbitrary duration of 60 days, although three quarters of our study cohort underwent extubation within 10 days of age. Finally, we acknowledge that, like any retrospective analysis, our study may have failed to capture all the variables that can influence the outcome of interest.

Strengths of the current study were the inclusion of most eligible infants using well-defined inclusion criteria with limited selection bias. While acknowledging the limitations of single center studies, one possible advantage to the single center cohort study is limited variability in clinical criteria used by clinicians for extubation and reintubation and a more consistent approach to the multiple aspects of NICU care. Our results are further validated by our use of a bootstrapping method, which leads to distribution-free estimates of the standard errors and confidence intervals [34, 35].

The extubation readiness estimator might serve to provide risk stratification information for future studies of various interventions aimed at improving the likelihood of extubation success. The role of this extubation estimator to improve neonatal outcomes can only be performed through a prospective randomized controlled trial.

\section{Conclusion}

Among extremely preterm infants, factors associated with successful extubation on adjusted analysis, following the first elective attempt included greater gestational age, chronologic age at extubation, higher blood gas $\mathrm{pH}$ before extubation, and lower pre-extubation $\mathrm{FiO}_{2}$, along with lower values for highest RSS in the first $6 \mathrm{~h}$ of age. We used these readily available clinical and demographic data to create an extubation readiness estimator that provides the probability of extubation success for individual premature infants who receive MV (http://elasticbeanstalk-us-east-2-676799334712. s3-website.us-east-2.amazonaws.com/). This estimator might serve to provide risk stratification information for future studies of various interventions aimed at improving the likelihood of extubation success.

\section{Compliance with ethical standards}

Conflict of interest The authors declare that they have no conflict of interest.

Publisher's note: Springer Nature remains neutral with regard to jurisdictional claims in published maps and institutional affiliations. 


\section{References}

1. Stoll BJ, Hansen NI, Bell EF, Walsh MC, Carlo WA, Shankaran S, et al. Trends in care practices, morbidity, and mortality of extremely preterm neonates. 1993-2012. JAMA. 2015;314:1039-51.

2. Walsh MC, Morris BH, Wrage LA, Vohr BR, Pool WK, Tyson JE, et al. Extremely low birthweight neonates with protracted ventilation: mortality and 18-month neurodevelopmental outcomes. J Pediatr. 2005;146:798-804.

3. Sant'Anna GM, Keszler M. Weaning infants from mechanical ventilation. Clin Perinatol. 2012;39:543-62.

4. Miller JD, Carlo WA. Pulmonary complications of mechanical ventilation in neonates. Clin Perinatol. 2008;35:273-81. x-xi

5. Jensen EA, DeMauro SB, Kornhauser M, Aghai ZH, Greenspan JS, Dysart KC. Effects of multiple ventilation courses and duration of mechanical ventilation on respiratory outcomes in extremely low-birth-weight infants. JAMA Pediatr. 2015;169:1011-7.

6. Berger J, Mehta P, Bucholz E, Dziura J, Bhandari V. Impact of early extubation and reintubation on the incidence of bronchopulmonary dysplasia in neonates. Am J Perinatol. 2014;31:1063-72.

7. Chawla S, Natarajan G, Shankaran S, Carper B, Brion LP, Keszler $\mathrm{M}$, et al. Markers of successful extubation in extremely preterm infants, and morbidity after failed extubation. J Pediatr. 2017; 189:113-.e112.

8. Giaccone A, Jensen E, Davis P, Schmidt B. Definitions of extubation success in very premature infants: a systematic review. Arch Dis Child Fetal Neonatal Ed. 2014;99:F124-127.

9. Hermeto F, Martins BM, Ramos JR, Bhering CA, Sant'Anna GM. Incidence and main risk factors associated with extubation failure in newborns with birth weight $<1250$ grams. J Pediatr. 2009;85:397-402.

10. Kirpalani H, Millar D, Lemyre B, Yoder BA, Chiu A, Roberts RS. A trial comparing noninvasive ventilation strategies in preterm infants. N Engl J Med. 2013;369:611-20.

11. Epstein SK, Ciubotaru RL, Wong JB. Effect of failed extubation on the outcome of mechanical ventilation. Chest. 1997;112:186-92.

12. Baisch SD, Wheeler WB, Kurachek SC, Cornfield DN. Extubation failure in pediatric intensive care incidence and outcomes. Pedia Crit Care Med. 2005;6(May):312-8.

13. Manley BJ, Doyle LW, Owen LS, Davis PG. Extubating extremely preterm infants: predictors of success and outcomes following failure. J Pediatr. 2016;173:45-9.

14. Shalish W, Latremouille S, Papenburg J, Sant'Anna GM. Predictors of extubation readiness in preterm infants: a systematic review and meta-analysis [published online ahead of print March 8]. Arch Dis Child Fetal Neonatal Ed. 2019;104:F89-97. https://doi.org/10.1136/archdischild-2017-313878.

15. Al-Mandari H, Shalish W, Dempsey E, Keszler M, Davis PG, Sant'Anna G. International survey on periextubation practices in extremely preterm infants. Arch Dis Child Fetal Neonatal Ed. 2015; 100:F428-431.

16. Tapia-Rombo CA, De León-Gómez N, Ballesteros-Del-Olmo JC, Ruelas-Vargas C, Cuevas-Urióstegui ML, Castillo-Pérez JJ. Predictors factors for the extubation failure in two or more times among preterm newborn. Rev Invest Clin. 2010;62:412-23.

17. Hiremath GM, Mukhopadhyay K, Narang A. Clinical risk factors associated with extubation failure in ventilated neonates. Indian Pediatr. 2009;46:887-90.

18. Bohn DJ, James I, Filler RM, Ein SH, Wesson DE, Shandling B, et al. The relationship between $\mathrm{PaCO}_{2}$ and ventilation parameters in predicting survival in congenital diaphragmatic hernia. J Pediatr Surg. 1984;19:666-71.

19. Ballard RA, Truog WE, Cnaan A, Martin RJ, Ballard PL, Merrill $\mathrm{JD}$, et al. Inhaled nitric oxide in preterm infants undergoing mechanical ventilation. N Engl J Med. 2006;355:343-53.

20. Ballard JL, Khoury JC, Wedig K, Wang L, Eilers-Walsman BL, Lipp R. New Ballard Score, expanded to include extremely premature infants. J Pediatr. 1991;119:417-23.

21. Finer NN, Carlo WA, Walsh MC, Rich W, Gantz MG, Laptook AR, SUPPORT Study Group of the Eunice Kennedy Shriver NICHD Neonatal Research Network et al. Early CPAP versus surfactant in extremely preterm infants. N Engl J Med. 2010; 362:1970-9.

22. Manley BJ, Owen LS, Doyle LW, Andersen CC, Cartwright DW, Pritchard MA, et al. High-flow nasal cannulae in very preterm infants after extubation. N Engl J Med. 2013;369:1425-33.

23. Dimitriou G, Fouzas S, Vervenioti A, Tzifas S, Mantagos S. Prediction of extubation outcome in preterm infants by composite extubation indices. Pediatr Crit Care Med. 2011;12: e242-249.

24. Kavvadia V, Greenough A, Dimitriou G. Prediction of extubation failure in preterm neonates. Eur J Pediatr. 2000;159:227-31.

25. Kamlin CO, Davis PG, Morley CJ. Predicting successful extubation of very low birthweight infants. Arch Dis Child Fetal Neonatal Ed. 2006;91:F180-183.

26. Chawla S, Natarajan G, Gelmini M, Kazzi SN. Role of spontaneous breathing trial in predicting successful extubation in premature infants. Pediatr Pulmonol. 2013;48:443-8.

27. Gillespie LM, White SD, Sinha SK, Donn SM. Usefulness of the minute ventilation test in predicting successful extubation in newborn infants: a randomized controlled trial. J Perinatol. 2003;23:205-7.

28. Mueller M, Almeida JS, Stanislaus R, Wagner CL. Can machine learning methods predict extubation outcome in premature infants as well as clinicians? J Neonatal Biol. 2013;2:1000118.

29. Vento G, Tortorolo L, Zecca E, Rosano A, Matassa PG, Papacci $\mathrm{P}$, et al. Spontaneous minute ventilation is a predictor of extubation failure in extremely-low-birth-weight infants. J Matern Fetal Neonatal Med. 2004;15:147-54.

30. Kaczmarek J, Chawla S, Marchica C, Dwaihy M, Grundy L, Sant'Anna GM. Heart rate variability and extubation readiness in extremely preterm infants. Neonatology. 2013;104:42-48.

31. Laughon MM, Langer JC, Bose CL, Smith PB, Ambalavanan L, Kennedy KA, et al. Prediction of bronchopulmonary dysplasia by postnatal age in extremely premature infants. Am J Respir Crit Care Med. 2011;183:1715-22.

32. Kuzniewicz MW, Puopolo KM, Fischer A, Walsh EM, Li S, Newman TB, et al. A quantitative, risk-based approach to the management of neonatal early-onset sepsis. JAMA Pediatr. 2017; 171:365-71

33. Ferguson KN, Roberts CT, Manley BJ, Davis PG. Interventions to improve rates of successful extubation in preterm infants: a systematic review and meta-analysis. JAMA Pediatr. 2017; 171:165-74.

34. Blackstone EH. Breaking down barriers: helpful breakthrough statistical methods you need to understand better. J Thorac Cardiovasc Surg. 2001;122(Sep):430-9.

35. Brunelli A, Rocco G. Internal validation of risk models in lung resection surgery: bootstrap versus training-and-test sampling. J Thorac Cardiovasc Surg. 2006;131(Jun):1243-7. 